\title{
Corrosion Inhibition Studies on Copper in Aqua Regia with Phenylazo-2-naphthol
}

\author{
P. MOHAMED SIRAJUDEEN* ${ }^{*}$ and R. SURYA PRIYADHARSHINI
}

Department of Chemistry, Khadir Mohideen College, Adirampattinam-614701, India

drpmsiraj@yahoo.in

Received 2 June 2015 / Accepted 25 June 2015

\begin{abstract}
The inhibition efficiency of various concentrations of phenylazo-2-naphthol on thecorrosion of copper in $1 \mathrm{~N}$ aqua regia $\left(\mathrm{HCl}+\mathrm{HNO}_{3}\right)$ was investigated by weight loss method at room temperature. The corrosion rate of copper and surface coverage of the inhibitor on the metal surface was also calculated from the weight loss data. The open circuit potential values of the system substantiate the corrosion behavior data. Langmuir adsorption isotherm concept was experimented to the adsorption behavior of inhibitor.
\end{abstract}

Keywords: Copper, Inhibitor, Aqua regia, Open Ciruit Potential, Adsorption

\section{Introduction}

Copper and its alloys are widely used in materials for their excellent chemical and thermal conductivities in many applications such as electronics ${ }^{1}$ and in the manufacture of integrated circuits $^{2-4}$. Copper is relatively noble metal, requiring strong oxidants for its corrosion or dissolution. The chemical dissolution and electrolytic plating are the main processes used in the fabrication of electronic devices.

The most widely used corrosive solutions contain $\mathrm{HNO}_{3}, \mathrm{HCl}$ and $\mathrm{H}_{2} \mathrm{SO}_{4}$. So these medium have induced a great deal of research on copper corrosion ${ }^{5-19}$. The use of chemical inhibitors is one of the most practical methods for the protection against corrosion in acidic media. The most prominent corrosion inhibitors are organic compounds containing nitrogen, sulphur, oxygen and phosphorous in their functional groups $\mathrm{s}^{20-23}$. The mechanism of these compounds has been proposed to be the adsorption, by means of lone pairs of electron, of the organic functional groups on the metal surfaces ${ }^{24}$.

The aim of the present work is to study the inhibition of copper corrosion in aquaregia with phenylazo-2-napthol at room temperature by weight loss method.

\section{Experimental}

Creep resistant and high strength of $2 \mathrm{~mm}$ thickness with the composition of copper (Cu:99.27\%, Sn:0.73\%) metal was used throughout the study. Copper sheet was cut into panels of size $5 \times 2.5 \mathrm{~cm}$. Holes were provided on the center of the peripherals of top of each panel. 
The panels of copper were polished and degreased with trichloroethylene and weighed to an accuracy of $10^{-4} \mathrm{~g}$. Sufficient number of triplicate panels were used in the immersion studies.

The inhibitor used in this study was phenylazo-2-napthol. The molecular formula of the inhibitor is $\mathrm{C}_{16} \mathrm{H}_{12} \mathrm{~N}_{2} \mathrm{O}$ with molecular mass of $248 \mathrm{~g} / \mathrm{mol}$. The chemical structure of phenylazo-2-napthol is shown in Figure 1.

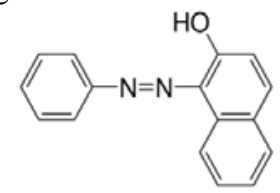

Figure 1. Structure of phenylazo-2-napthol

From the mass of the inhibitor and its molecular weight relation, appropriate concentrations of the inhibitor were prepared by dilution. The corrosive medium used was $1 \mathrm{~N}$ solution of aqua regia.

Weight loss method

The prepared copper samples were fully immersed in inhibited solutions of $0.0012,0.0014$, 0.0017 and $0.0020 \mathrm{mM}$ concentrations. The duration of weight loss experiment was 2 hours as per API Standard experimental procedure. The experiment was carried out at room temperature. After 2 hours the specimens were removed, washed with distilled water, dried and reweighed. The weight loss of all the samples was calculated. From the weight loss, the corrosion rate was determined using the relationship ${ }^{25,26}$.

$$
\text { Corrosion rate }(\mathrm{mmpy})=\left(\frac{87.6 \times \mathrm{w}}{D x A x T}\right)
$$

Where $\mathrm{w}$ is the weight loss in $\mathrm{mg}, \mathrm{D}$ is the Density in $\mathrm{g} / \mathrm{cc}, \mathrm{A}$ is the area of exposure in $\mathrm{cm}^{2}$, mmpy is millimeter per year.

The inhibition efficiency was also determined from the following relationship ${ }^{27-29}$.

$\left.\begin{array}{c}\text { Inhibition } \\ \text { efficiency }(\%)\end{array}\right\}=\frac{\text { Weight loss without inhibitor-weight loss with inhibitor }}{\text { Weight loss without inhibitor }} \times 100$

The surface coverage $(\theta)$ of the inhibitor has been obtained from the following formula ${ }^{30,31}$.

Surface coverage $(\theta)=\frac{\text { Weight loss without inhibitor - weight loss with inhibitor }}{\text { Weight loss without inhibitor }}$

\section{Results and Discussion}

Weight loss measurements

The inhibition of copper corrosion in $1 \mathrm{~N}$ aqua regia by phenylazo-2-napthol was studied at room temperature by weight loss method. In this study, the parameters like inhibition efficiency (\%), corrosion rate (mmpy), open circuit potential (ocp-mv), surface coverage $(\theta)$, activation energy $\left(\mathrm{E}_{\mathrm{a}}\right)$ and free energy of adsorption $\left(\Delta G_{\mathrm{ads}}\right)$ were determined.

\section{Open circuit potential of copper in acid}

The OCP values in the presence of inhibitor at various concentrations are much lesser than the OCP value in the absence of inhibitor. Table 1 shows the OCP values of copper in $1 \mathrm{~N}$ aqua regia with absence and presence of inhibitor. The OCP values and corrosion rates of copper in the aquaregia have the same trend throughout the study. 
Table 1. OCP Values for the corrosion of copper in $1 \mathrm{~N}$ aqua regia with varying concentration of inhibitor at room temperature

\begin{tabular}{|c|c|c|}
\hline S.No & Concentrations of inhibitor, $\mathrm{mM}$ & OCP vs. SCE $10^{-3} \mathrm{mV}$ \\
\hline 1 & Blank & -0.510 \\
\hline 2 & 0.0012 & -0.491 \\
\hline 3 & 0.0014 & -0.478 \\
\hline 4 & 0.0017 & -0.474 \\
\hline 5 & 0.0020 & -0.470 \\
\hline
\end{tabular}

\section{Effect of change in the concentration of the inhibitor}

The effect of concentration of inhibitor on corrosion rate and inhibition efficiency was studied by varying the concentration of the inhibitor from $0.0012 \mathrm{Mm}$ to $0.0020 \mathrm{mM}$ in aqua regia.

The results are summarized in Table $2 \&$ 3. The values given in the table show that inhibition efficiency increases with increase in concentration of the inhibitor and correspondingly there is a decrease in the corrosion rate. The maximum efficiency was reached with inhibitor concentration of $0.0020 \mathrm{Mm}$.

Table 2. Corrosion rate (mmpy) values for the corrosion of copper in $1 \mathrm{~N}$ aqua regia with varying concentration of inhibitor at room temperature

\begin{tabular}{ccc}
\hline S.No & Concentrations of inhibitor, $\mathrm{mM}$ & Corrosion rate $\times 10^{-3} \mathrm{mmpy}$ \\
\hline 1 & Blank & 16.24 \\
2 & 0.0012 & 0.89 \\
3 & 0.0014 & 0.83 \\
4 & 0.0017 & 0.76 \\
5 & 0.0020 & 0.53 \\
\hline
\end{tabular}

Table 3. Inhibition efficiency (\%) values for the corrosion of copper in $1 \mathrm{~N}$ aqua regia with varying concentration of inhibitor at room temperature

\begin{tabular}{ccc}
\hline S. No & Concentration of inhibitor, $\mathrm{mM}$ & Inhibition efficiency, \% \\
\hline 1 & Blank & - \\
2 & 0.0012 & 94.71 \\
3 & 0.0014 & 94.95 \\
4 & 0.0017 & 95.12 \\
5 & 0.0020 & 96.74 \\
\hline
\end{tabular}

In the present study, a thorough analysis of the results presented in Table $3 \& 4$ reveal that the inhibition efficiency and surface coverage values increases with increasing concentration of inhibitor.

Table 4. Surface coverage values for the corrosion of copper in $1 \mathrm{~N}$ aqua regia with varying concentration of inhibitor at room temperature

\begin{tabular}{ccc}
\hline S.No & Concentration of inhibitor, $\mathrm{mM}$ & Surface coverage, $\theta$ \\
\hline 1 & Blank & - \\
2 & 0.0012 & 0.947 \\
3 & 0.0014 & 0.949 \\
4 & 0.0017 & 0.951 \\
5 & 0.0020 & 0.967 \\
\hline
\end{tabular}


This observation indicates that the inhibition of copper corrosion in aqua regia by the inhibitor occurs through adsorption mechanism. A review of literature suggest that organic compound and their derivatives such as azoles ${ }^{32-37}$, amines, amino acids and many others showed inhibition effect for the corrosion of copper and copper alloys in different media.

\section{Effect of nature of inhibitor}

In general, organic molecules are adsorbed on liquid and solid surface in their flat orientation $^{38}$. The flat orientation of organic inhibitor molecules is more prominent among the aromatic compounds due to the strong interaction of $\pi$ - electrons of aromatic ring with the metal surface ${ }^{39}$.

In addition if the inhibitor molecules, posses groups such $\mathrm{C}=\mathrm{N}, \mathrm{C}=\mathrm{O}, \mathrm{C}=\mathrm{S}, \mathrm{N}=\mathrm{N}$, etc., the $\pi$ electrons from these groups also interact with metal surface which will be facilitated again by the flat orientation of the molecule $\mathrm{e}^{40,41}$. The interaction of the unshared electron pairs on the hetero atom such as oxygen, nitrogen, phosphorous and sulphur also aid in the process of adsorption.

Finally, the protonated inhibitor molecules may electrostatically interact with the anions of the aggressive medium pre adsorbed on the metal surface ${ }^{42}$. All the four kinds of interactions may contribute to the adsorption of mechanism or one of them may predominate over the other depending on the nature of the metal surface, inhibitor molecules and aggressive medium.

\section{Adsorption isotherm}

Adsorption isotherms are very important in understanding the mechanism of inhibiton of corrosion reaction. The degree of surface coverage $(\theta)$ at different concentrations of the inhibitor is one of the factors considered in this test and was measured from weight loss data.

$$
\frac{\theta}{1-\theta}=K_{a d s} C
$$

Where $\theta$ is the degree of surface coverage, $\mathrm{K}$ is the adsorption equilibrium constant and $\mathrm{C}$ is the concentration of the corrosion inhibitor.

On consideration of the Langmuir-Freundlich adsorption isotherm, which is well described in the literature ${ }^{43-48}$, it has been found that the experimental data gave a straight line graph on a plot of $\log (\theta / 1-\theta) v s . \log C$ and fitted the adsorption isotherm shown in Figure 2. The Langmuir-Freundlich isotherm assumes a monolayer adsorption of the inhibitor molecules on the metal surface ${ }^{49-51}$.

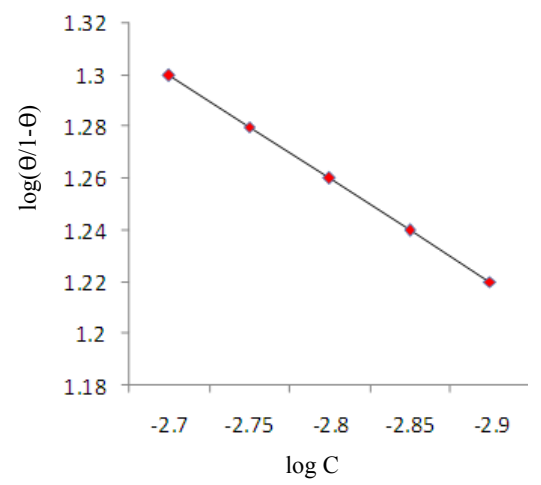

Figure 2. Langmuir-Freundlich isotherm 


\section{Free energy of adsorption $\left(\Delta G_{a d s}\right)$}

The values of free energy of adsorption were calculated from $\theta$ values at room temperature. The equilibrium constant of adsorption $\mathrm{K}$ is related to the standard free energy of adsorption ${ }^{52,53}$.

$$
\begin{gathered}
\Delta G_{\mathrm{ads}}=-\mathrm{RT} \ln (55.5 \mathrm{k}) \\
\mathrm{K}=\theta / \mathrm{C}(1-\theta)
\end{gathered}
$$

Where $\mathrm{R}$ is the gas constant, $\mathrm{T}$ is the absolute temperature and 55.5 is the concentration of water in solution in $\mathrm{mol} / \mathrm{L}$. The value of free energy of adsorption for the inhibitor concentration of 0.0020 is equal to $-8502.79 \mathrm{~kJ}$. The negative values of $\Delta G_{\text {ads }}$ indicate the spontaneous adsorption of the inhibitor on the surface of copper and are usually characteristic of strong interaction of inhibitor with the metal surface.

\section{Conclusion}

1. Phenyl azo-2-naphthol acts as efficient corrosion inhibitor in $1 \mathrm{~N}$ aqua regia.

2. The adsorption of inhibitor obeys Langmuir-Freundlich isotherm.

3. The inhibition efficiency of the inhibitor increases with increase in concentration suggested the physical adsorption of the inhibitor on the metal Surface.

4. The inhibitor gives very high inhibition efficiencies even with very small concentration of the order of $0.0020 \mathrm{Mm}$.

5. The less negative free energy values suggest physisorption of the inhibitors on the metal surface.

\section{References}

1. Oteino-Alergo V, Huynh N, Notoya T, Bottle S E and Schwcinsberg D P, Corros Sci., 1999, 41(4), 685-697; DOI:10.1016/S0010-938X(98)00138-3

2. Ho C E, Chen W T and Kao C R, J Electron Mater, 2001, 30(4), 379-385; DOI:10.1007/s11664-001-0047-6

3. Tsai H Y, SunS C and Wang S J, J Electrochem Soc., 2000, 147(7), 2766-2772; DOI:10.1149/1.1393604

4. Krishnamoorthy A, Chanda K, Murarka S P, Ramanath G and Ryan J G, Appl Phys Lett., 2001, 78(17), 2467-2469; DOI:10.1063/1.1365418

5. Evans U R, Trans Farad Soc., 1944, 40, 120-130; DOI:10.1039/TF9444000120

6. Krosilshchikov A I and Dedova I V, J Gen Chem U.S.S.R., 1946, 16, 537.

7. Komuro Y, J Chem Soc Jpn., 1954, 75, 255.

8. Travincek E A and Weber J H, J Phys Chem., 1961, 65, 235.

9. Smol'yaninov I S and Voronezhsk I, Gos Ped Inst., 1964, 47, 34.

10. Rasheed Arain A and Shams El Din A M, Thermochim Acta, 1985, 89, 171-185; DOI:10.1016/0040-6031(85)85493-9

11. Zarrouk A, Dafali A, Hammouti B, Zarrok H, Boukhris S and Zertoubi M, Int J Electrochem Sci., 2010, 5, 46-55.

12. A.Zarrouk, Chelfi T, Dafali A, Hammouti B, Al-Deyab S S, Warad I, Benchat N and Zertoubi M, Int J Electrochem Sci., 2010, 5, 696-705

13. Zarrouk A, Warad I, Hammouti B, Dafali A, Deyab S S A and Benchat N, Int J Electrochem Sci., 2010, 5, 1516-1526.

14. Zarrouk A, Hammouti B, Dafali A and Zarrok H, Der Pharma Chemica., 2011, 3(4), 266-274.

15. Fouda A S, Gouda M M and Abd El-Rahman S I, Bull Korean Chem Soc., 2000, 21(12), 1085-1089. 
16. Khaled K F and Mohammed A Amin, Corros Sci., 2009, 51(9), 2098-2106; DOI:10.1016/j.corsci.2009.05.038

17. Khaled K F, Sahar A Fadl-Allah and Hammouti B, Mater Chem Phys., 2009, 117(1), 148-155; DOI:10.1016/j.matchemphys.2009.05.043

18. Mihit M, Laarej K, Abou El Makarim, H, Bazzi L, Salghi R and Hammouti B, Arab J Chem., 2010, 3(1), 55-60; DOI:10.1016/j.arabjc.2009.12.009

19. Fiala A, Chibani A, Darchen A, Boulkamh A and Diebbar K, Appl.Surf.Sci., 2007, 253(24), 9347-9356; DOI:10.1016/j.apsusc.2007.05.066

20. Sachin H P, Khan M H M and Bhujangaiah N S, Int J Electrochem Sci., 2009, 4(1), 134-143.

21. Umoren S A, Eduok U M and.Oguzie E E, Portugaliae Electrochimica Acta, 2008, 26(6), 533-546.

22. Kumar A, J Chem., 2008, 5(2), 275-280; DOI:10.1155/2008/574343

23. Maayta A K, Fares M M and Al-Shawabkeh A F, Int J Corros., Article ID 156194,9 pages, 2010; DOI:10.1155/2010/156194

24. Niamien P M, Trokourey A and Sissouma D, Int J Res Chem Environ., 2012, 2(4), 204-214.

25. Bhat J I and Alva V, Indian J Chem Technol., 2009, 16(3), 228-233.

26. Abdallah M, Megahed H E,.Radwan MA and Abdfattah E, J Am Sci., 2012, 8(11), 49-55.

27. Akpan I A and Offiong N O, Chem Mater Res., 2012, 2(7), 40-47.

28. Akpan I A, Bull Pure Appl Sci., 2012, 31(2), 49-58.

29. Shylesha B S, Venkatesha T V and Praveen B M, Res J Chem Sci., 2011, 1(7), 46-50.

30. Cang H, Fei Z, Shao J, Shi W and Xu Q, Int J Electrochem Sci., 2013, 8, 720-734.

31. Mistry B M, Patel N S and Jauhari S, Arch Appl Sci Res., 2011, 3(5), 300-308.

32. Khaled K F, Electrochim Acta, 2009, 54(18), 4345-4352;

DOI:10.1016/j.electacta.2009.03.002

33. Yu P, Liao D M, LuoY B and Chen Z G, Corros., 2003, 59, 314.

34. Scendo M and Hepel M, J Electroanal Chem., 2008, 613(1), 35-50; DOI:10.1016/j.jelechem.2007.10.014

35. Zucchi F, Trabanelli G and Fonsati M, Corros Sci., 1996, 38(11), 2019-2029; DOI:10.1016/S0010-938X(96)00094-7

36. El Issami S, Bazzil, Mihit M, Hammouti B, Kertit S, Ait ADDI E and Salghi R, Pigm ResinTechnol., 2007, 36(3), 161-168; DOI:10.1108/03699420710749027

37. Mihit M, El Issami S, Bouklah M, Bazzi L, Hammouti B, Ait ADDI E, Salghi R and Kertit S, Appl Surf Sci., 2006, 252(6), 2389-2395; DOI:10.1016/j.apsusc.2005.04.009

38. Bockris J O'M, Green M and Swinkels D A J, J Electrochem Soc., 1964, 111(6), 743-748; DOI:10.1149/1.2426223

39. Pamfilov A V and Kuzub V S, Khim Ukr Zh., 1962, 28, 528.

40. Chen S, Li S, Lei S, Houyima,Yu R and Liu D, Corros Sci., 1999, 41(7), 1273-1287; DOI:10.1016/S0010-938X(98)00183-8

41. Hariharaputhran, Subramanian A, Antony A A, Sankar P M, Gopalan Vasudevan T and Iyer S V K, Br Corros J., 1998, 33, 214.

42. Frignani A, Monticell C, Brunoro G, Zucchini M and Omer I H, Br Corros J., 1987, 22, 103.

43. Mobin M, Praveen M and Alam Khan M, Recent Res Sci Technol., 2011, 3(12), 40-45.

44. Quraishi M A and Sardar R, Indian J Chem Technol., 2004, 11(1), 103-107. 
45. Nnanna L A, Obasi V U, Nwadiuko O C, Mejeh K I, Ekewe N D and Udensi S C, Arch Appl Sci Res., 2012, 4(1), 207-217.

46. Khadom A A, Yaro A S, Altaie A S and Kadum A A H, Portugaliae Electro Chimica Acta, 2009, 27(6), 699-712.

47. Khalifa O R M, Kassab A K, Mohamed H A and Ahmed S Y, J Am Sci, 2010, 6(8), 487-498.

48. Chitra S, Parameswari K and Selvaraj A, Int J Electrochem Sci., 2010, 5, 1675-1697.

49. Joseph B, John S, Joseph A and Narayana B, Indian J Chem Technol., 2010, 17(5), 366-374.

50. Chitra S, Parameswari K, Vidhya M, Kalishwari M and Selvaraj A, Int J Electrochem Sci., 2011, 6, 4593-4613.

51. Bilgic $\mathrm{S}$ and Caliskan N, Appl Surf Sci., 1999, 152(1-2), 107-114; DOI:10.1016/S0169-4332(99)00308-6

52. Khamis E, Corrosion, 1990, 46(6), 476-484.

53. Zaafarany I A, Int J Electrochem Sci., 2013, 8, 9531-9542. 